\title{
MICROCOMPUTER-CONTROLLED POLAROGRAPHIC INSTRUMENTATION AND ITS USE IN THE DETERMINATION OF STABILITY CONSTANTS OF CROWN ETHER COMPLEXES
}

\author{
D. Ph. ZOLLINGER, M. BOS, A. M. W. VAN VEEN-BLAAUW and \\ W. E. VAN DER LINDEN* \\ Department of Chemical Technology, Twente University of Technology, Enschede \\ (The Netherlands)
}

(Received 16th July 1984)

\section{SUMMARY}

A computer-controlled polarographic system is described, based on a commercially available polarograph interfaced to a microcomputer. Experiments are controlled and monitored entirely from software, including automatic evaluation of the Tast polarograms and addition of solutions to the polarographic cell from a motor burette. The program was written in FORTH, a computer language especially apt for laboratory automation. The system is used in the determination of stability constants of crown ether complexes.

Crown ethers and related compounds are capable of forming complexes with small polar organic molecules, as reported by Pedersen [1]. Little atten. tion seems to have been paid to this finding in the years following its publication until recently; since 1982 several papers dealing with this subject have appeared [2-6]. This reflects the potential significance that is attached to complexes of this nature.

For the determination of the stability constants of these complexes in polar solvents, no direct method was available; therefore, the present authors developed a procedure based on an extension of the method of DeFord and Hume [7]. The extension was necessary because of the electro-inactivity of the compounds of interest. It makes use of the competition between the small organic molecule (e.g., urea) and an alkali metal ion for the crown compound. To obtain reliable and precise values for the stability constants, it is necessary to evaluate the half-wave potential and the limiting current of the reduction waves as accurately as possible. Automation of the procedure is a suitable means to achieve this goal. This paper describes the use of a microcomputer for the control of a polarograph, for real-time data acquisition and data processing, for the addition of solutions to the polarographic cell by means of a motor burette, and for the overall control of the experiments. 


\section{PROGRAMS}

Laboratory automation demands versatile computer programs, capable of executing such different tasks as real-time overall control of the experiment and (on-line) evaluation of the data. In the case of electrochemical instrumentation, the two major requirements for computerized control of the experiment are real-time data acquisition (with an analog-to-digital converter, $A D C$ ) and software control of the potential regime (by means of a digital-to-analog converter, DAC). Evaluation of the data includes disk storage, establishment of the number of waves/peaks in the voltammogram and quantification of the individual waves/peaks.

The characteristics of a good laboratory computer language can be formulated on the basis of these different tasks required from the computer program [8]. These characteristics will include the possibility of using variables, constants and named procedures and functions as well as applying repetitive and conditional statements. Additional features are a capacity to extend the language and the possibility of defining new data structures. It should also be possible to share procedures among different users (re-entrance) and to use them in a recursive way. Finally, all functions should be available in an interactive mode. A more detailed treatment of the subject has been given recently by Dessy $[8,9]$.

Although machine-code programming offers the advantage of high speed, which is necessary for fast data-acquisition routines, it lacks nearly all the properties of a good laboratory language. Frequently, this problem is overcome by using Assembly programming for the time-critical parts of the program and embedding these codes in a program written in a high-level language (such as BASIC, FORTRAN or PASCAL) for the over-all control of the experiment. This advantage of speed, however, is achieved at the expense of system portability, which is becoming more important for laboratory automation. To achieve the best compromise between these options, it was decided to write the program for the (overall) control of the experiment in FORTH and to use machine-code as little as possible.

FORTH seems to be the best language for the domain of real-time laboratory data acquisition and control: it is easy to write, occupies little memory, executes rapidly and contains most of the characteristics of a good laboratory language. Like other high-level languages, it provides some important advantages over assembly language programming: system portability, structured programming, modularity and easier documentation. It permits rapid generation of structured programs, designed top-down and coded bottom-up, mainly because of its property of vocabulary expansion: the user can produce new definitions (words), based on words previously defined, which are linked together sequentially from words in the existing (system) dictionary.

Unlike high-level languages like FORTRAN or PASCAL, in which subroutines can be used in a main program only, FORTH offers real-time interactive programming and debugging: every word is available to the user for testing or use in other routines. 


\section{Assembly routines}

For timing and AD/DA conversion, three words were defined by using FORTH assembly language. The parameters for these words, which are expected to be on the stack, are given in parentheses: (1) ADIN (channel no.) produces a $A / D$ conversion at the specified channel number and puts the result on the stack; (2) DASET (mV value, channel no.) produces a D/A conversion at the specified channel number and adds an output voltage of the specified value to the potentiostat voltage; (3) TIMSTART (ms interval) starts the real-time clock routine with the specified interval in milliseconds. Synchronization of the timing of the microprocessor clock and the mercury drop hammer was achieved by monitoring the output of the hammer drive of the polarographic stand (Fig. 1) and starting the timing for the drop life at the moment of the knock-off signal.

\section{FORTH program}

Apart from the three words given above, the program for the recording of the polarograms, the storage of the data and their evaluation was written entirely in (high-level) FORTH language. A public domain version of FORTH, developed at the Laboratory of Experimental Physics, State University of Utrecht (The Netherlands), was used. This version has utilities such as file handling, printer drivers, floating point arithmetic and graphics (FysForth version 02/03).

The program is built up from words defined for specific tasks that have to be done during the experiment, e.g., keyboard input of the experimental parameters (START), definition of drop time (TDR), storage of the data in memory on disk (SAVEDATA) and the determination of the number of waves in the polarograms from the number of zero crossings in the second derivative of the d.c. polarogram (ZERO). An example of the design of the program is given in Fig. 2, where the definitions of the words RUN, TAST and TASTSCAN are given. These words are all in (high-level) FORTH and they make use of the assembly-language words mentioned above. RUN takes care of the recording of a polarogram, storage of the data on disk and evaluation of the data.

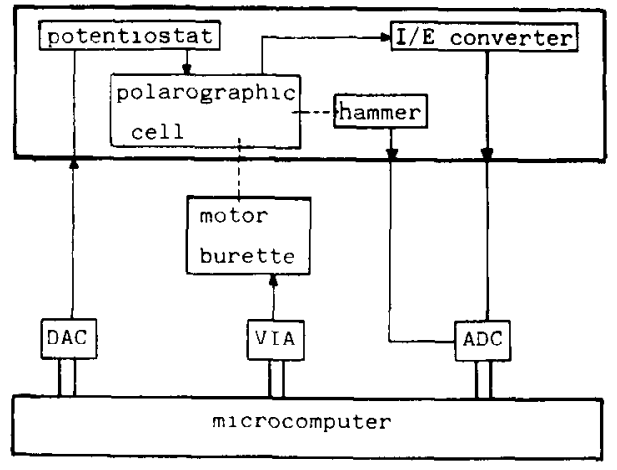

Fig. 1. Hardware: interfacing of the polarograph to the microcomputer. 


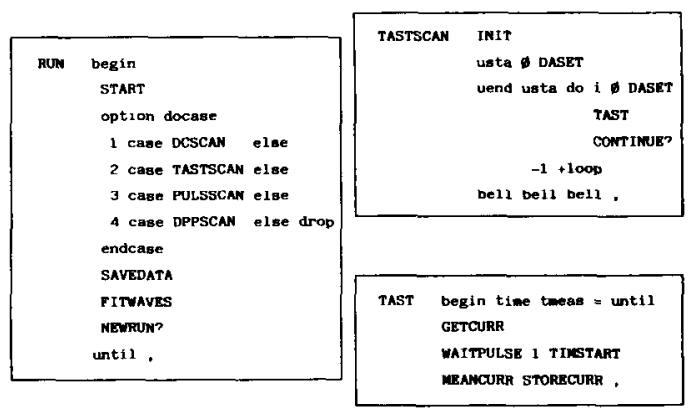

Fig. 2. FORTH program: definition of the words RUN, TASTSCAN and TAST.

The input for the program is initiated by the word START. Input parameters for the recording part are mode (d.c., Tast, normal or differential pulse), initial and final potential, drop time, scan rate and current sensitivity for the polarograph. After the polarogram has been recorded, the data, together with an appropriate identifier (character string), can be stored on disk for use by other programs (SAVEDATA). The format of the storage enables the disks to be read by FORTH as well as by UCSD PASCAL programs. Next, the data of the current run are evaluated automatically (FITWAVES). A simple routine (SPKTST) scans the data for spikes and/or dips, caused by premature drop fall, and replaces these by extrapolated values. Subsequently, the data are subjected to a three-parameter procedure for curve-fitting as described by Bos [10], which yields the half-wave potential, limiting current value and slope of the logarithmic plot. Finally, ligand solution can be added to the polarographic cell and the user can proceed to a new run of the program (NEWRUN?). A word used by RUN is TASTSCAN, which initiates recording of a Tast polarogram. After initialization of the experimental parameters (INIT), the potential is set to the initial potential by using the assembly word DASET. In a loop, the potential is changed from initial to final potential (USTA and UEND, respectively) and for every potential the current is sampled (TAST). The word CONTINUE? is used for monitoring the keyboard: if a key was pressed, the recording of the polarogram is stopped if the appropriate keyboard command was entered; otherwise, execution of the program will continue. TAST, finally, is used by the word TASTSCAN for the current sampling at the end of a mercury drop life. The current is sampled at a given moment TMEAS; then after the pulse of the hammer and the start of timing for the new drop (WAITPULSE 1 TIMSTART) the mean current (of the previous drop) is calculated and stored in memory.

Other words such as FITWAVES or SAVEDATA are built up in the same way as described for the word RUN, and every word is available to the user for immediate execution. 


\section{EXPERIMENTAL}

\section{Chemicals and instrumentation}

Benzo-15-crown and dibenzo-24-crown-8 (Merck) were used as received. 18-Crown-6 (Merck) was purified from the acetonitrile complex as described by Gold and Rice [11]. All other chemicals were of at least analyticalreagent grade and were used as received.

A Metrohm E506 polarograph was used in conjunction with the E505 polarographic stand. A platinum wire served as counter electrode. A doublejunction silver/silver chloride reference electrode was used; the inner electrolyte was a saturated solution of lithium chloride in ethanol and the outer electrolyte was the supporting electrolyte solution.

A Basis 108 microcomputer was used for the computerization of the polarograph. The computer, equipped with two processors (6502 and Z80) and 128 kbytes of RAM, has built-in serial and parallel interfaces and six additional slots for expansion cards. Four of these slots were used for disk controller, DAC, ADC and VIA. A Radiometer autoburette ABU-12 a (total volume $2.5 \mathrm{ml}$ ) was driven from the computer by a TTL signal using a 6522 VIA. Ligand solutions were added to the polarographic cell in fixed-volume increments of $0.01 \mathrm{ml}$ (accuracy $0.1 \%$ ).

The current-time function output of the polarograph was connected to the microcomputer by means of a 12-bit ADC (ADC-16-12-2K-TMR; Digilog, Enschede, The Netherlands) and a 12-bit DAC (APL 06; Kronemuis, available from Manudax, Heeswijk, The Netherlands) was connected to the pilot voltage input of the polarograph (Fig. 1).

In order to circumvent problems from noise contributions, the current was sampled during one period of the line frequency $(20 \mathrm{~ms})$ at the maximum rate of the $\mathrm{ADC}$ and its associated data-acquisition software (i.e., $2.9 \mathrm{kHz}$ ) and the average of these values was taken as the actual current value. In this way, an accuracy of $\pm 0.1 \%$ was obtained and multiple experiment averaging was unnecessary.

The computerization of the polarograph did not require any modification of the commercially available instrument, so that it remained available for non-automated use (e.g., for a.c. polarography which was not implemented in the computerized version).

\section{Procedure}

Nitrogen, saturated with the solvent to be used, was led through the metal ion solutions for $25 \mathrm{~min}$ in order to remove oxygen and for a further $1-2 \mathrm{~min}$ after each addition of the concentrated solution of the crown ether from the burette.

The polarograms were recorded at a scan rate of 4 or $5 \mathrm{mV} \mathrm{s}^{-1}$, the drop time being set at 0.8 or $1.0 \mathrm{~s}$, while the polarographic cell was kept at $25.0 \pm$ $0.1^{\circ} \mathrm{C}$ with a Tamson thermostat. 


\section{RESULTS AND DISCUSSION}

The advantages of the use of FORTH language became especially apparent during the initial program development. Because new words can be defined in an interactive mode and are available to the user not only in a program environment but also individually, debugging of the programs is simple and fast. Moreover, compilation is fast in comparison to other systems, which further facilitates testing of new programs. A second important feature of FORTH programs is the intrinsic speed of the routines: evaluation of a typi-

\section{TABLE 1}

Half-wave potential, limiting current value and reciprocal slope of the log plot for the reductions of cadmium and rubidium ions

$$
\begin{array}{lll}
-E_{1 / 2}(\mathrm{~V}) & I_{\mathrm{d}}(\mu \mathrm{A}) & \text { Slope }^{-1}(\mathrm{mV})
\end{array}
$$

\begin{tabular}{lccc}
\hline $8 \times 10^{-5} \mathrm{M} \mathrm{Cd}^{2+}$ in aqueous $0.1 \mathrm{M} \mathrm{KCl}(\mathrm{n}=8)$ & & \\
Range & $0.5539-0.5549$ & $0.709-0.7215$ & $28.69-30.08$ \\
Mean & 0.5543 & 0.717 & 29.43 \\
S.d. & 0.0003 & 0.004 & 0.43 \\
3.4 $\times 10^{-4} \mathrm{M} \mathrm{Rb}^{+}$in $0.1 \mathrm{M} \mathrm{TEAI}$ in methanol $(\mathrm{n}=11)$ & \\
Range & $1.889-1.892$ & $0.852-0.878$ & $58.4-61.4$ \\
Mean & 1.890 & 0.864 & 59.9 \\
S.d. & 0.0012 & 0.010 & 1.0 \\
\hline
\end{tabular}

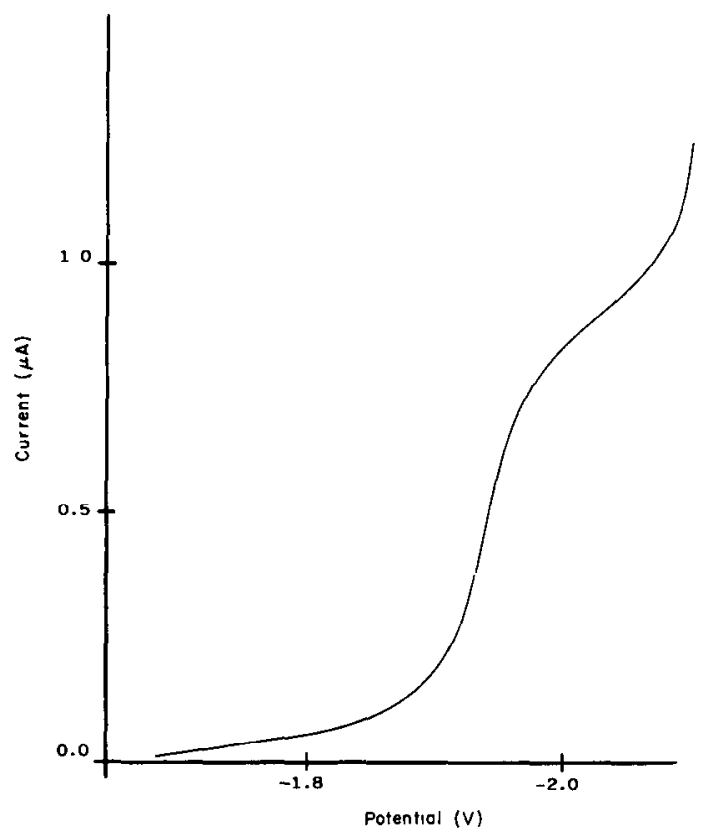

Fig. 3. Polarogram of $3.4 \times 10^{-4} \mathrm{M} \mathrm{RbCl}$ in $0.1 \mathrm{M}$ TEAI in methanol. 
TABLE 2

Stability constants of some crown ether complexes in methanol. Comparison of manual and fully computerized method

\begin{tabular}{|c|c|c|c|c|c|c|}
\hline \multirow{2}{*}{$\begin{array}{l}\text { Ligand/ } \\
\text { metal }\end{array}$} & \multirow[t]{2}{*}{ Ligand } & \multirow[t]{2}{*}{ Metal } & \multicolumn{2}{|l|}{ Manual } & \multicolumn{2}{|c|}{ Computerized } \\
\hline & & & $\log K^{a}$ & Data s.d. ${ }^{b}\left(10^{-3}\right)$ & $\log K^{\mathrm{a}}$ & Data s.d.b $\left(10^{-3}\right)$ \\
\hline \multirow[t]{6}{*}{$1: 1$} & B15C5 & $\mathrm{Na}$ & - & & $2.97(0.01)$ & 1.2 \\
\hline & & $\mathbf{R b}$ & $3.11(0.05)$ & 6.3 & $3.12(0.03)$ & 3.4 \\
\hline & $18 \mathrm{C} 6$ & $\mathrm{Na}$ & $4.44(0.05)$ & 9.0 & $4.43(0.03)$ & 4.6 \\
\hline & & $\mathbf{R b}$ & $5.47(0.04)$ & 6.1 & $5.43(0.02)$ & 3.4 \\
\hline & DB24C8 & $\mathrm{Na}$ & - & & $2.35(0.01)$ & 0.4 \\
\hline & & $\mathbf{R b}$ & $3.74(0.02)$ & 3.5 & $3.83(0.01)$ & 1.3 \\
\hline \multirow[t]{2}{*}{$2: 1$} & B15C5 & $\mathbf{R b}$ & $2.77(0.07)$ & & $2.90(0.03)$ & 0.9 \\
\hline & & & $5.45(0.07)$ & 1.5 & $5.37(0.04)$ & 0.9 \\
\hline
\end{tabular}

aStandard deviation in parentheses. ${ }^{\mathrm{b}} \mathrm{Standard}$ deviation of experimental data used for evaluation.

cal polarogram takes $45-60 \mathrm{~s}$, while evaluation of the data by a PASCAL program takes about $90 \mathrm{~s}$.

The accuracy of data acquisition by the computerized system was tested by evaluating the repeatability of the parameters of the polarographic reduction waves. For this purpose, an aqueous solution of cadmium ions and a solution of rubidium ion in methanol were used. Half-wave potential and limiting current can be determined very precisely for the cadmium solution (Table 1). In the case of the less well-defined reduction wave of the rubidium ion in a methanolic solution of tetraethylammonium iodide (TEAI), (Fig. 3), the precision is again good, which is prerequisite for obtaining precise results in the determination of stability constants of alkali-metal ion complexes.

Stability constants for a number of these complexes for three different crown ethers were determined by means of the computerized system. The results are in good agreement with previously determined values (Table 2). When the automated evaluation was used, the time needed for the evaluation of a polarogram was reduced by a factor of 5-10 in comparison to a manual method. Moreover, the computerized system yields more precise values for the stability constants: the standard deviation of the experimental data is reduced by a factor of about 2 .

The authors thank Mr. J. Heezen for his help with the computerization of the instrumentation and Mr. R. Joosten for his advice on the use of the FysForth software package. These investigations were supported (in part) by the Netherlands Foundation for Technical Research (STW), future Technical Science Branch Division of the Netherlands Organization for the Advancement of Pure Research (ZWO). 


\section{REFERENCES}

1 C. J. Pedersen, J. Org. Chem., 36 (1971) 1690.

2 J. A. A. de Boer, J. W. H. M. Uiterwijk, J. Geevers, S. Harkema and D. N. Reinhoudt, J. Org. Chem., 48 (1983) 4821.

3 J. A. A. de Boer, D. N. Reinhoudt, S. Harkema, G. J. v. Hummel and F. de Jong, J. Am. Chem. Soc., 104 (1982) 4073.

4 J. W. H. M. Uiterwijk, S. Harkema, J. Geevers and D. N. Reinhoudt, J. Chem. Soc. Chem. Commun., (1982) 200.

5 A. Elbasyouny, H. J. Brügge, K. v. Deuten, M. Dickel, A. Knöchel, K. U. Koch, J. Kopf, D. Melzer and G. Rudolph, J. Am. Chem. Soc., 105 (1983) 6568.

6 W. H. Watson, J. Galloy, D. A. Grossie, F. Vögtle and W. M. Müller, J. Org. Chem., 49 (1984) 347.

7 D. Ph. Zollinger, M. Bos, A. M. W. van Veen-Blaauw and W. E. van der Linden, Anal. Chim. Acta, 161 (1984) 83.

8 R. E. Dessy, Anal. Chem., 55 (1983) 650A.

9 R. E. Dessy, Anal. Chem., 55 (1983) 756A.

10 M. Bos, Anal. Chim. Acta, 81 (1976) 21.

11 H. S. Gold and M. R. Rice, Talanta, 29 (1980) 637. 